\title{
Iranian EFL Learners' Attitudes Toward Language Learning Through Social Media During the Covid-19 Pandemic
}

\author{
Mehdi Haghi Kabeteh
}

\begin{abstract}
The current research aimed at exploring Iranian English as a foreign language (EFL) learners' attitudes and perceptions toward learning a language by means of social media during the outbreak of the Covid-19 pandemic. To do so, 850 participants were selected voluntarily based on inclusion criteria from 1000 language learners enrolling in the general English courses at some specific institutions and under some tutors. To collect the intended data, a researcher-made questionnaire, devised based on the available literature to scrutinize their attitude using 5-point Likert scale items, was administered by means of social media to the participants. Out of the collected questionnaires, 850 were included for the analysis in this research. The results revealed that EFL learners consider social media as a significant element of their learning a foreign language, especially throughout the Covid-19 pandemic. The findings of the present research can pave the way for the inclusion of social media as an indispensable instrument of nurturing collaboration and communication among learners even after the pandemic eases.
\end{abstract}

Keywords: EFL learners, social media, the covid-19 pandemic, attitudes and perceptions, language learning DOI: $10.7176 / \mathrm{NMMC} / 96-03$

Publication date:May $31^{\text {st }} 2021$

\section{Introduction}

Nowadays, social media have become omnipresent. That is, social media are a key fragment of our lives, and a big fraction of population around the globe spend many hours on Twitter, YouTube, Facebook, etc. around the world (Eren, 2012). The growth of Web 2.0 tools, designated as the web-based services preparing users with textual, audio-visual, and interactive information, has caused social media to become very well-known and widespread (O'Reilly, 2007), and this, in turn, has motivated academics to scrutinize the possibility of the use of social media in teaching/learning processes, in general, (Tilfarlioglu, 2011) and EFL learning/teaching contexts in particular, especially during the Covid-19 pandemic. It is at the present time argued that social media plays a massive role for delivering a quality education corresponding to the social settings of learning (Aloraini, 2018; Mason, 2006). Some researchers even argued that social media might revolutionize educational system entirely so as to inspire students for a better learning rather than being participants passive in a classroom (Ziegler, 2007). Even though social media are not unswervingly envisioned for educational determinations, they have attracted a great deal of attention from EFL teachers/learners because they function as a didactic instrument inside the foreign (and even second) language learning/teaching contexts. From a social constructivist point-of-view, foreign language (FL) learning is looked upon both as an individual process/activity and it is also a cooperative activity, and in an FL learning setting main mental processes are hypothetically eased by means of social media (Mondahl \& Razmerita, 2014). In this regard, Sekiguchi (2012) stated that rising dynamic FL/L2 learning atmosphere is an important element in order to help EFL learners, and the role played by social media when integrated into the EFL curriculum to decisively and suitably promote communities of learning in which EFL learners would regularly take part cannot be ignored.

Furthermore, social media can make richer mental images available for learners, in so doing smoothing learning a language since it can present learning materials in more than one modality (Smith, Alvarez-Torres, \& Zhao, 2003), that is, in addition to written texts, learners can be exposed to audio-visual materials as well. The students make use of them all the time. Among them, Facebook, Wiki, YouTube, bulletin board, LinkedIn, blogging, and twittering are most popular. Since platforms of social media (PSMs) have put an end to the limitations the physical world faces, that is, users will not face time and location limitations, and PSMs offer limitless communicative chances in the computer-generated world, they have been more and more popular to complement EFL/ESL learning (Fewell, 2014). Social learning is referred to as the learning offered by means of social media applications, that is, the learners are social learners if they use social media in order to learn. This means that the present-day language learners, in general, are responsive to making use of such PSMs as social networks (e.g., LinkedIn, Facebook, Instagram, etc.), content communities (e.g., YouTube), collaborative projects (e.g., Wiki), blogs/microblogs (e.g., Twitter), and virtual social worlds (e.g., Second Life) as well as some others facilities for group meetings (e.g., Skype, Zoom, Google Meet, etc.) (Kaplan \& Haenlein, 2010).

Since PSMs have come to characterize an important setting in the area of FL/L2 learning/teaching, it is presumed that the EFL learners' attitudes toward social media may provide academics including teachers, learners, curriculum developers, decision-makers of the realm, etc. with invaluable information about the strengths and weaknesses of it and direct the people involved in teaching/learning activities and investigators in 
additional exploration on the issue. Consequently, the current research aimed at examining Iranian EFL learners' attitudes toward language learning through social media during the Covid-19 pandemic. The study, in addition, aimed to uncover whether independent variables such as grade, gender, and frequency of using social media impact on EFL learners' attitudes toward the use of social media in learning a language. Furthermore, the present research sought to discover the role that social media plays in EFL learners' language learning. To this end, the following research questions were formulated:

1. What is the frequency of using social media and how does it impact on EFL learners' attitudes toward language learning by means of social media during the Covid-19 pandemic?

2. What are Iranian EFL learners' attitudes toward language learning by means of social media during the Covid-19 pandemic?

3. What are the roles social media play in EFL learners' language learning experiences during the Covid19 pandemic?

\section{Literature review}

In the EFL/ESL learning/teaching context, some researchers shed some light on different PSMs with regard to their uses, potentials, etc. including Instagram (Akhiar, Mydin, \& Kasuma, 2017; Aloraini, 2018; Anggraeni, 2017; Gonulal, 2019; Mansor, \& Rahim, 2017; Sari, \& Wahyudin, 2019), YouTube (Balbay, \& Kilis, 2017; Fleck, Beckman, Sterns, \& Hussey, 2014; Kabooha, \& Elyas, 2018; Maziriri, Gapa, \& Chuchu, 2020), Facebook (Atmaca, 2013; Bailey, Park, \& Haji, 2017; Çakır, \& Atmaca, 2015; Shukor , 2015; Terantino, 2013), Twitter (Cheng, 2012; Kim, Park, \& Baek, 2017; Mompean, \& Fouz-González, 2016; Said, \& Abd Elfatah , 2015; Taskiran, Gumusoglu, \& Aydin, 2018), Skype (Eaton, 2010, Elia, 2006; Ockert, 2015, 2020; Yen, Hou, \& Chang, 2015), Zoom (Cheung , 2021; Khusniyah, 2020; Nuryanto, 2021; Serhan, 2020), and What's App (Hamad, 2017; Noorani, \& Salehi, 2019; Suadi, 2021).

In line with the research in this venue, Aloraini $(2018$, p. 1) collected data from true EFL usage from the comments segment of 15 Instagram IDs that were targeting the Saudi learners as their population. To this end, totally, 140 comments were analyzed ( 70 for grammar plus 70 for vocabulary). The results of a non-parametric Mann-Whitney test "indicated a statistical significance $Z(140)=-2.38$, p. $=017$ for output, with a relatively small effect size $(\mathrm{d}=.438)$, showing that vocabulary posts elicited more output from the commenters." In addition, Liu, (2010, p. 1), in 2009 at University of Houston, examined student's making use of diverse social media apparatuses, their preference of social networking groups, and their perceptions and attitudes toward these tools, and findings disclosed that the three top-used social media tools are Wikipedia, Facebook, and YouTube; that the top four reasons why they used social media tools are for the sake of "social engagement, direction communication, speed of feedback, and relationship building. Regarding social networking group, they preferred a group of civically engaged and no membership required as well as a group based on contemporary topic that may not last long."

In addition to the above-mentioned research studies, Al-Qaysi, Mohamad-Nordin, and Al-Emran (2019) conducted a study entitled "What leads to social learning? Students' attitudes towards using social media applications in Omani higher education" in order to measure the students' attitudes toward making use of social media from different perspectives including social media application, gender, governorate, age, experience, year of study, and interest. To this end, a total of 1307 students attending to eight dissimilar universities/colleges located in eight far apart governorates in Oman took part by means of an online survey. Their findings displayed that age, gender, experience, governorate, and interest are of momentous influences on students' attitudes. However, the social media applications and study years have not had any substantial consequence on their attitudes. In addition, WhatsApp was the most principal application which was used for the sake of education.

The available literature shows that over the past few years, social media have influenced human lives in a way which is unique in its degree and scale. Of course, education in general and EFL/ESL instruction in particular has not been left intact from its influence. In this unexpected rare situation of a worldwide lockdown due to the outbreak of the Covid-19 pandemic that has redefined and intricated intercontinental borders, simultaneously, the restriction of physical mobility has led to an upwardly mobile, determined generation of home-bound persons to one more time experience PSMs with an even greater retribution. Throwing on state-ofthe-art roles, PSMs have captured novel prospects and come to play a leading role in distribution of scientific information, sustained education, online discussions, peer review, and many more during the current Covid-19 pandemic.

\section{Methodology}

\subsection{Research Design and Setting}

This research followed a quantitative experimental research approach, which was carried out from March 2020 to March 2021 during the Covid-19 pandemic in Iran. 


\subsection{Sampling Procedure and Participants}

More than 1000 EFL learners enrolled in the English Language Teaching institutes and tutors under consideration for this research during this period of the Covid-19 pandemic out of which the study sample (850) was selected based on some criteria including (a) their participation in online courses during the pandemic, (b) desire to complete the questionnaire, and (c) the completion of the questionnaire in a proper way. All of the participants were Iranian (Turkish, Persian, Kurdish, etc. speakers) with a mean age of 25.3 ranging from 15 to 46 years. Of the chosen sample, $700(82.35 \%)$ were female and $150(17.65 \%)$ were male EFL learners, all having different language proficiency (A1, A2, B1, B2, C1, and C2). It should be mentioned that the participation was voluntary, that the participants were made sure that their given responses (and the collected data as a whole) will only be used for the sake of research, that their personal information will be kept confidential, and that their participation will not influence their scores on the course.

\subsection{Data Collection Procedures}

In this quantitative research, the data were collected using a researcher-made questionnaire based on the reviewing the relevant literature. Before administering it, the questionnaire was presented to two experts in the field of TEFL who agreed that it is measuring what it purports to, that is, it has content validity. In addition, they argued that it has face validity as well. Then, it was piloted on 30 EFL learners. The Cronbach's alpha reliability coefficient of the questionnaire was calculated to be .85 , which proved that the scale was reliable enough to be administered to the participants.

The questionnaire, which is composed of three sections. As usual, its first part obtained demographic information (gender, age, grade, English proficiency, etc.) from the participants. Its second part considers some items about their use of social media. And the last part of the questionnaire includes an attitude scale comprising of 22 items in a 5-point Likert scale and intends to quantity the participants' attitudes toward learning a language by means of social media during the covid-19 pandemic. The questionnaire was administered online by means of some social media (Telegram, LinkedIn, Twitter, etc.) to 850 EFL learners chosen to function as the study sample who had enrolled in the online English language teaching programs during the pandemic.

\subsection{Data Analysis Procedures}

After administering the questionnaire by means of social media to the sample, the data collected using the questionnaires were analyzed by means of IBM SPSS Statistics 25. Simple descriptive statistics (range, minimum, maximum, frequencies, standard deviations [SD], and mean) were tabulated in order to identify the participants' attitudes toward the use of social media in language learning throughout the Covid-19 pandemic. Then, one-way ANOVA were computed to examine the relationship between the independent variables such as academic year, gender, frequency of social media use and the dependent variable, that is, EFL learners' attitudes toward language learning by means of social media during the lock-down period due to the spread of Covid-19.

\section{Results}

In the following sub-sections, the data related to each and every research question will sequentially be presented separately. The first sub-section will present the data related to the first research question.

1. What is the frequency of using social media and how does it impact on EFL learners' attitudes toward language learning by means of social media during the Covid-19 pandemic?

A one-way ANOVA was performed to understand whether frequency of using social media influences EFL learners' attitudes toward language learning by means of social media during the Covid-19 pandemic.

Table 1. EFL Learners' Attitudes toward Language Learning by Means of Social Media in Terms of Frequency of Using Social Media during the Covid-19 Pandemic

\begin{tabular}{l|llllll}
\multicolumn{2}{l}{} & SUM OF SQUARES & DF & MEAN SQUARES & F & P \\
\hline \multirow{2}{*}{ ATTITUDES } & Between groups & 4.319 & 2 & 2.159 & .251 & 0.046 \\
& Within groups & 6853.62 & 798 & 8.588 & & \\
& Total & 6857.939 & 800 & & &
\end{tabular}

As presented in Table 1, there was statistically significant difference at the $p<.05$ level in EFL learners' attitudes toward learning a language by means of social media during the Covid-19 pandemic for the frequency of using social media $F(2,798)=.251, p=.046$. That is, frequency of social media use during the Covid-19 pandemic has effect on the attitudes of the EFL learners toward the use of social media in language learning. In the following sub-section, the data related to the second research question is presented in Table 2 .

2. What are Iranian EFL learners' attitudes toward language learning by means of social media during the Covid-19 pandemic?

To answer the second research question, the gathered data by means of the administered questionnaire were tabulated as Table 2, which shows the findings on the participants' attitudes toward EFL learning by means of social media during the Covid-19 pandemic. 
Table 2. The Iranian EFL Learners' Attitudes toward Language Learning by means of Social Media during the Covid-19 Pandemic

$$
\text { 萄 }
$$

A language learner is more self-directed and flexible while employing social media during the Covid-19 pandemic.

I am skeptical about the use of social media in language learning during the Covid-19 pandemic.

Language learning is more collaborative when using social media during the Covid-19 pandemic.

Learning a language by means of social media can aid me to improve my studies during the Covid-19 pandemic.

Social media can aid me develop my writing skills during the Covid-19 pandemic.

Social media can aid me learn wherever I wish during the Covid-19 pandemic.

Social media can assist me in becoming a more self-confident language user during the Covid-19 pandemic.

Social media can enable me plan and organize my own studies better during the Covid-19 pandemic.

Social media can make language learning more accessible during the Covid-19 pandemic.

Social media can motivate me to persist in studying, even when I feel like giving up during the Covid-19 pandemic.

Social media could help me develop my EFL communication skills during the Covid-19 pandemic.

Social media could help me develop my EFL grammar during the Covid-19 pandemic.

Social media could help me develop my EFL listening skills during the Covid-19 pandemic.

Social media could help me develop my EFL pronunciation during the Covid-19 pandemic.

Social media could help me develop my EFL reading skills during the Covid-19 pandemic.

Social media could help me develop my EFL speaking skills during the Covid-19 pandemic.

Social media could help me develop my EFL vocabulary knowledge during the Covid-19 pandemic.

Social media could help me learn in ways matching my personality and needs during the Covid-19 pandemic.

Social media forms a more relaxed and stress-free EFL learning environment during the Covid-19 pandemic.

Social media provides EFL learners with access to more real-life language use during the Covid-19 pandemic.

Using social media can help me become a more motivated EFL learner during the Covid-19 pandemic.

Using social media in language learning can assist me incorporate better into the world I live in during the Covid-19 pandemic.

As seen in Table 2, almost all (843 out of 850) of the participants completely agreed that "Social media can aid me learn wherever I wish during the Covid-19 pandemic.", which is the most highly agreed item. The second highest totally agreed (819 out of 850 ) was "Social media can aid me develop my writing skills during the Covid-19 pandemic." On the other hand, "I am skeptical about the use of social media in language learning during the Covid-19 pandemic." Was the highest totally disagreed item (753 out of 850). With regard to the language skills (speaking, reading, listening, and writing) and components (vocabulary and grammar) as well as some other aspects (e.g., pronunciation, communication, etc.), it can be understood that writing (819 out of 850), grammar (781 out of 850), vocabulary knowledge (756 out of 850), reading (731 out of 850), communication (694 out of 850), pronunciation (627 out of 850), speaking (598 out of 850), listening (536 out of 850), are in a 
descending order of the participants' total agreement with regard to the use of social media and its positive influence during the Covid-19 pandemic. Having carefully considered the data with regard to the skills and components, it can be understood that the more concrete skills and components such as writing, grammar and vocabulary knowledge were more influenced by means of social media on the eye of EFL learners during the Covid-19 pandemic, while other less tangible aspects and skills such as listening, speaking, pronunciation, and communication have been less influenced. This means that the type of skill the learners are exposed to might not only change their success of failure, but it might also change the attitude of the EFL learners with regard to the use of social media in EFL/ESL instruction, especially during the lock-down period. In the forthcoming subsection, the data related to the third research question is presented in Table 3.

3. What is the role of social media in EFL learners' language learning experiences during the Covid-19 pandemic?

To answer the third research question, the collected data with regard to the role of social media in EFL learners' language learning experiences during the Covid-19 pandemic was analyzed.

Table 3. The Role of Social Media in EFL Learners' Language Learning Experiences during the Covid-19 Pandemic

The role of social media on EFL learning during the Covid-19 pandemic Non-existent

An occasional addition of EFL learning during the Covid-19 pandemic A regular component of EFL learning during the Covid-19 pandemic The main medium of EFL learning during the Covid-19 pandemic Total

As Table 3 presented, descriptive statistics indicated that $97.29 \%$ of the EFL learners consider social media as a main medium of their language learning experiences during the lock-down period due to the outbreak of the Covid-19, whereas only $0.11 \%$ of them claimed that social media has no effect in their language learning throughout the period.

\section{Discussion and Conclusion}

This research aimed at figuring out the attitudes of Iranian EFL learners toward using social media during the lock-down period caused by the outbreak of the Covid-19 pandemic. To this end, three research questions were raised, and the relevant data in this regard were gathered using a researcher-made questionnaire from 800 Iranian EFL learners. Results of the study can be summarized based on the research questions so that the data can shed light on the issue under investigation.

The data in Table 2 revealed that EFL learners have positive attitudes toward the use of social media in language learning, which is in line with the previous research with regard to the use of social media in general (Akhiar, Mydin, \& Kasuma, 2017; Aloraini, 2018; Al-Qaysi, Mohamad-Nordin, \& Al-Emran, 2019; Bailey, Park, \& Haji, 2017; Balbay, \& Kilis, 2017; Eaton, 2010; Elia, 2006; Fewell, 2014; Fleck, Beckman, Sterns, \& Hussey, 2014; Kabooha, \& Elyas, 2018) and the use of social media during the pandemic (Cheung, 2021; Serhan, 2020; Suadi, 2021) in particular.

Some learners believed that social media could help them develop their vocabulary knowledge (Al-Qaysi, Mohamad-Nordin, \& Al-Emran, 2019). In addition, some learners argued that social media creates a more relaxed and stress-free language learning environment for them during the pandemic (Cheung, 2021; Serhan, 2020). Still another group of EFL learners argued that social media give EFL learners easy access to more authentic language use (Kabooha, \& Elyas, 2018).

Based on the majority of EFL learners, a language learner is more self-directed and flexible while using social media. The majority also agreed that social media can make language learning more accessible and feasible. As for language skills, most EFL learners argued that social media could help them develop not only their reading, writing, speaking, and listening skills but also the pronunciation, communication as well as their vocabulary knowledge and grammar, which is in line with the findings of some researchers (Terantino, 2013; Tilfarlioglu, 2011; Yen, Hou, \& Chang, 2015). Additionally, they believe that social media help them progress their studies and enable them to become more confident in not only learning the intended language but also using the language. Furthermore, they agreed that social media could inspire them more to learn a language. Last but not the least, they regarded learning a language by means of social media as more collaborative than the traditional learning approach, especially during the lock-down, because they believed that there is no other better way to teach and learn under such a circumstance.

In addition, the majority of the participants not only consider social media as a consistent constituent of their EFL learning experiences but they also stated that they are using social media regularly during the lockdown, which is in line with the findings of some researchers (Cheung, 2021; Serhan, 2020; Suadi, 2021).

Given that EFL learners perceived that regular use of social media during the pandemic could make noteworthy contributions to EFL learning, some pedagogical implications can be noted which might shed light 
on the issue under investigation. First, EFL learners can use social media as an instrument to improve their basic language skills not only during the pandemic but also after it eases. EFL teachers should use and help their students use social media by adapting social media, which is an entertaining platform, into an instructional tool, especially during the lock-down period. Curriculum developers can require social media in the process of foreign language teaching with constructivist teaching approaches. Moreover, from a socio-cultural point of view, social media, not only functions as an instrument for instruction, bit they also create a virtual atmosphere for mental development that is affected by society and culture of EFL students. Last but not the least, foreign language instructors should use social media as an instrument of development of student's interaction and communication in the target language.

Regarding the limitations faced during the implementation of the current research, the participants were limited to 800 EFL learners, and the study data was limited to the data from the paper-and-pencil researchermade questionnaire. Additional study may concentrate on other factors that may have an impact on EFL learners' attitudes toward learning a language by means of social media in dissimilar EFL contexts, under different circumstances other than lock-down, with descriptive, longitudinal, and experimental examination of making use of social media in FL teaching/learning within the lock-down period or beyond. It may also concentrate on glitches bumped into in the use of social media for language education. Still, another research of this type might consider comparing the perceptions of teachers and learners with regard to the use of social media.

\section{References}

Akhiar, A., Mydin, A. A., \& Kasuma, S. A. A. (2017). Students' perceptions and attitudes towards the use of Instagram in English language writing. Malaysian Journal of Learning and Instruction, 47-72.

Aloraini, N. (2018). Investigating Instagram as an EFL learning tool. Arab World English Journal (AWEJ) Special Issue on CALL, 4, 174-184.

Al-Qaysi, N., Mohamad-Nordin, N., \& Al-Emran, M. (2019). What leads to social learning? Students' attitudes towards using social media applications in Omani higher education. Education and Information Technologies, 25, 2157-2174.

Anggraeni, C. W. (2017, April). Students' perspectives toward the use of Instagram in writing class. In English Language and Literature International Conference (ELLiC) Proceedings (Vol. 1, pp. 68-74).

Atmaca, Ç. (2013). Student teachers and teacher educators' perceptions about the use of Facebook in English language teaching.

Bailey, D., Park, I., \& Haji, S. A. (2017). An investigation of Facebook for language learning: Better understanding perceptions and participation. Computer Assisted Language Learning Electronic Journal, 18(2), 14-30.

Balbay, S., \& Kilis, S. (2017). Students' perceptions of the use of a YouTube channel specifically designed for an academic speaking skills course. Eurasian Journal of Applied Linguistics, 3(2), 235-251.

Çakır, A., \& Atmaca, Ç. (2015). Pre-service teacher perceptions about the use of Facebook in English language teaching. Digital Culture \& Education, 7(2), 110-130.

Cheng, H. Y. (2012). Applying Twitter to EFL reading and writing in a Taiwanese college setting (Doctoral dissertation).

Cheung, A. (2021). Language teaching during a pandemic: A case study of Zoom use by a secondary ESL teacher in Hong Kong. RELC Journal, 0033688220981784.

Eaton, S. E. (2010). How to use Skype in the ESL/EFL classroom. The Internet TESL Journal, 16(11), 1-14.

Elia, A. (2006). Language learning in tandem via Skype. Reading Matrix: An International Online Journal, 6(3), 269-280.

Eren, Ö. (2012). Students' attitudes towards using social networking in foreign language classes: A Facebook example. Public Relations Journal, 4(3), 288-294.

Fewell, N. (2014). Social networking and language learning with Twitter. Research Papers in Language Teaching and Learning, 5(1), 223-234.

Fleck, B. K., Beckman, L. M., Sterns, J. L., \& Hussey, H. D. (2014). YouTube in the classroom: Helpful tips and student perceptions. Journal of Effective Teaching, 14(3), 21-37.

Gonulal, T. (2019). The use of Instagram as a mobile-assisted language learning tool. Contemporary Educational Technology, 10(3), 309-323.

Hamad, M. M. (2017). Using WhatsApp to enhance students' learning of English language: Experience to share. Higher Education Studies, 7(4), 74-87.

Kabooha, R., \& Elyas, T. (2018). The effects of YouTube in multimedia instruction for vocabulary learning: Perceptions of EFL students and teachers. English Language Teaching, 11(2), 72-81.

Kaplan, A. M., \& Haenlein, M. (2010). Users of the world, unite! The challenges and opportunities of social media. Business Horizons, 53(1), 59-68. 
Khusniyah, N. L. (2020). Teacher's perception on SQ4R in English reading comprehension learning using Zoom application. Voices of English Language Education Society, 4(2), 231-238.

Kim, E. Y., Park, S. M., \& Baek, S. H. (2011). Twitter and implications for its use in EFL learning. Multimedia Assisted Language Learning, 14(2), 113-137.

Liu, Y. (2010). Social media tools as a learning resource. Journal of Educational Technology Development and Exchange (JETDE), 3(1), 101-114.

Mansor, N., \& Rahim, N. A. (2017). Instagram in ESL classroom. Man in India, 97(20), 107-114.

Mason, R. (2006). Learning technologies for adult continuing education. Studies in Continuing Education, 28(2), $121-133$.

Maziriri, E. T., Gapa, P., \& Chuchu, T. (2020). Student perceptions towards the use of YouTube as an educational tool for learning and tutorials. International Journal of Instruction, 13(2), 119-138.

Mompean, J. A., \& Fouz-González, J. (2016). Twitter-based EFL pronunciation instruction. Language Learning \& Technology, 20(1), 166-190.

Mondahl, M., \& Razmerita, L. (2014). Social media, collaboration and social learning: A case-study of foreign language learning. Electronic Journal of E-Learning, 12(4), 339-352.

Noorani, A., \& Salehi, H. (2019). The impact of using WhatsApp on Iranian intermediate EFL learners' acquisition of compound nouns: Gender in focus. In The sixth national symposium of literature, knowledge, and technology proceeding.

Nuryanto, M. (2021). Fostering success and motivating EFL learners using Zoom meeting: A synchronous learning strategy. Anglophile Journal, 1(2), 1-12.

Ockert, D. (2015). Increases in Japanese EFL learners' motivation, international posture, and interest in foreign language activities after skype exchanges. Digital Culture \& Education, 7(2b), 205-226.

Ockert, D. (2020). Skype ${ }^{\circledR}$ international EFL exchanges revisited: Chi-squared results of changes in affective variables. Teaching English with Technology, 20(2), 66-81.

O'reilly, T. (2007). What is Web 2.0: Design patterns and business models for the next generation of software. Communications \& Strategies, 65(1), 17-37.

Rosell-Aguilar, F. (2018). Twitter as a formal and informal language learning tool: From potential to evidence. In F., Rosell-Aguilar, T., Beaven, \& M. F. Gutiérrez, (Eds.), Innovative language teaching and learning at university: Integrating informal learning into formal language education, (pp. 99-106).

Said, A., \& Abd Elfatah, M. (2015). The effect of Twitter on developing writing skill in English as a foreign language. Arab World English Journal (AWEJ) Special Issue on CALL, 2, 134-149.

Sari, F. M., \& Wahyudin, A. Y. (2019). undergraduate students' perceptions toward blended learning through Instagram in English for business class. International Journal of Language Education, 3(1), 64-73.

Serhan, D. (2020). Transitioning from face-to-face to remote learning: Students' attitudes and perceptions of using Zoom during Covid-19 pandemic. International Journal of Technology in Education and Science, 4(4), 335-342.

Shukor, S. S. (2015). ESL Students' Perceptions on the use of Facebook as a collaborative writing tool in improving writing performance. AJELP: Asian Journal of English Language and Pedagogy, 3, 205-227.

Smith, B., Alvarez-Torres, M. J., \& Zhao, Y. (2003). Features of CMC technologies and their impact on language learners' online interaction. Computers in Human Behavior, 19(6), 703-729.

Suadi, S. (2021). Students' perceptions of the use of Zoom and WhatsApp in ELT amidst Covid19 pandemic. Study of Applied Linguistics and English Education, 2(01), 51-64.

Taskiran, A., Gumusoglu, E. K., \& Aydin, B. (2018). Fostering foreign language learning with Twitter: What do English learners think about it? Turkish Online Journal of Distance Education, 19(1), 100-116.

Terantino, J. M. (2013). Facebook comparison research: Faculty and student perceptions of social media for foreign language courses. In Computer-assisted foreign language teaching and learning: Technological advances (pp. 91-103). IGI Global.

Tilfarlioglu, F. Y. (2011). An international dimension of the student's attitudes towards the use of English in Web 2.0 technology. Turkish Online Journal of Educational Technology, 10(3), 63-68.

Yen, Y. C., Hou, H. T., \& Chang, K. E. (2015). Applying role-playing strategy to enhance learners' writing and speaking skills in EFL courses using Facebook and Skype as learning tools: A case study in Taiwan. Computer Assisted Language Learning, 28(5), 383-406.

Ziegler, S. (2007). The (mis)education of Generation M. Learning, Media and Technology, 32(1), 69-81. 


\section{Appendix A}

\section{Questionnaire}

Part 1

Age:

Gender:

English proficiency:

The course they take:

The name of the institute or tutor:

Number of years you have been learning English:

\section{Part 2}

Answer the following items carefully based on the instructions.

How often do you use social media for EFL learning during the covid-19 pandemic? (Select one choice.)

Choice

One a month

Twice a month

Trice a month

Once a week

Twice a week

Trice a week

Four times a week

More than four times a week

How many hours of courses have you had online through social media during the pandemic? (Write a number.) Which social media have you used during the pandemic for learning EFL such as Facebook, Twitter, YouTube, etc.? (You can select more than one choice.)

\begin{tabular}{|l|l|}
\hline Choice & Put a checkmark here \\
\hline YouTube & \\
\hline Twitter & \\
\hline Facebook & \\
\hline Google Meet & \\
\hline Zoom & \\
\hline Adobe Connect & \\
\hline Skype & \\
\hline Instagram & \\
\hline Telegram & \\
\hline Other & \\
\hline
\end{tabular}

Did you use only voice facility of social media (Google Meet, Zoom, Adobe Connect, etc.) or share screen, and chat and sharing camera as well?

\begin{tabular}{|l|l|}
\hline Choice & Put a checkmark here \\
\hline Voice only & \\
\hline Voice and share screen & \\
\hline Voice, camera and share screen & \\
\hline Other & \\
\hline
\end{tabular}

Could you have an interaction during the lessons or was it unilateral (i.e., teacher-centered)?

\begin{tabular}{|l|l|}
\hline Choice & Put a checkmark here \\
\hline Unilateral (i.e., teacher-centered) & \\
\hline Bilateral & \\
\hline
\end{tabular}

Have you had any other previous experience of using social media for the sake of learning prior to the pandemic? (answer Yes/No)

\begin{tabular}{|l|l|}
\hline Choice & Put a checkmark here \\
\hline Yes & \\
\hline No & \\
\hline
\end{tabular}


The Role of Social Media in EFL Learners' Language Learning Experiences during the Covid-19 Pandemic: (Select one choice here.)

\begin{tabular}{|l|l|}
\hline Choice & Put a checkmark here \\
\hline Non-existent & \\
\hline An occasional addition of EFL learning during the Covid-19 pandemic & \\
\hline A regular component of EFL learning during the Covid-19 pandemic & \\
\hline The main medium of EFL learning during the Covid-19 pandemic & \\
\hline
\end{tabular}

Part 3

Based on 5-point Likert scale, answer the following items, and choose either 'totally agree', 'agree', 'neutral', 'disagree', or 'totally disagree'.

\begin{tabular}{|l|l|l|l|}
\hline & & \\
& & & \\
\hline A language learner is more self-directed and flexible while employing social media. & & & \\
\hline I am skeptical about the use of social media in language. & & & \\
\hline Language learning is more collaborative when using social media. & & & \\
\hline Learning a language through social media can aid me to improve my studies. & & & \\
\hline Social media can aid me to develop my writing skills. & & & \\
\hline Social media can aid me to learn wherever I wish. & & & \\
\hline Social media can assist me in becoming a more self-confident language user. & & & \\
\hline Social media can enable me to plan and organize my own studies better. & & & \\
\hline Social media can make language learning more accessible. & & & \\
\hline Social media can motivate me to persist in studying, even when I feel like giving up. & & & \\
\hline Social media could help me to develop my communication skills. & & & \\
\hline Social media could help me to develop my grammar. & & & \\
\hline Social media could help me to develop my listening skills. & & & \\
\hline Social media could help me to develop my pronunciation. & & & \\
\hline Social media could help me to develop my reading skills. & & & \\
\hline Social media could help me to develop my speaking skills. & & \\
\hline Social media could help me to develop my vocabulary knowledge. & & & \\
\hline Social media could help me to learn in ways matching my personality and needs. & & & \\
\hline Social media forms a more relaxed and stress-free language learning environment. & & & \\
\hline Social media provides learners with access to more real-life language use. & & \\
\hline Using social media can help me to become a more motivated language learner. & & \\
\hline Using social media in language learning can assist me to incorporate better into the \\
world I live in. & & & \\
\hline
\end{tabular}

